\title{
Introduction to Bioethics: The Boundary between Research and Clinical Practice
}

\section{Graciela Moya $^{1}$}

Biomedical research, seeking for scientific advances and new technologies, has produced substantial social benefits, optimal health care, increased expectancy, and improvement of the quality of life, especially for people living with illness [1].

The translation of new insights provided by basic biomedical research into innovative methods of diagnosis and therapy requires a strict safety and efficacy evaluation before it is being approved as a routine validated intervention [2]. All these promising advances also posed some troubling ethical questions [3].

Numerous documents referred to the protection of people and especially those in vulnerable situations in biomedical research have been published. More than 70 years ago the "Nuremberg Code" (1947) laid the groundwork for regulations on human experimentation [4]. Three basic elements became the foundation for subsequent codes of ethics and research regulations: voluntary informed consent, favorable risk-benefit analysis, and the right to withdraw without repercussions [5]. A year later the "Universal Declaration of Human Rights” (1948) [6] was announced, expressing acknowledge of the inherent dignity and the equal and inalienable rights of all members of the human family. However, after the publication of both documents, numerous events in clinical research affected the life, rights, or well-being of participants [7]. These events led to the publication and updating of new recommendations, such as the "Declaration of Helsinki" of 1964, adopted by the World

Medical Association, in an attempt to formulate a more specific international code of ethics [8]. As biomedical research efforts expanded, the Declaration has required nine subsequent updates, the last in 2013. The amended version of 1975 stated that research projects should be submitted to an independent research ethics committee for approbation and supervision. This committee must review the scientific quality of the research proposal and its conformity with national law, being its guiding framework for the protection, welfare, and safety of participants [9]. Therefore, these commissions have a central role in the research process by improving the truthfulness and quality of clinical research [10].

But despite the existence of these recommendations, the lack of recognition of the protection of people who participate in clinical research persisted. In 1979, another document, the "Belmont Report" was published. This report aim is to serve as the basis for international regulations for the protection of participants in clinical research [11]. The report establishes three general ethical principles understood as basic: (1) Respect for with two moral requirements: to acknowledge autonomy and to protect those with diminished autonomy; (2) Beneficence, that recognize two general principles: Do not harm and maximize possible benefits minimizing possible harms; and 3- Justice, with equally burdens and benefits represented in these formulations: To each person an equal share, to each person

${ }^{1}$ Department of Bioethics, Facultad de Ciencias Médicas, Pontificia

Universidad Católica Argentina, Argentina, South America.

Address of Correspondence

Dr. Graciela Moya, MD, PhD,

Instituto de Bioética, Pontificia Universidad Católica Argentina, Argentina,

South America.

E-mail: gracielamoya@uca.edu.ar

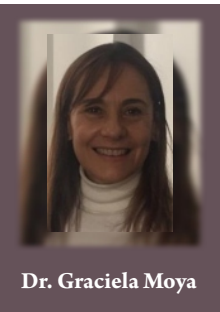

according to individual need.

New ethical challenges arise with multinational or transnational expansion of research, that results from different needs and conditions of low and limited resources settings. In 1982 the Council for International Organizations of Medical Sciences and the World Health Organization developed together the "International Ethical Guidelines for Biomedical Research Involving Human Subjects" with the aim to provide an internationally ethical framework "designed to be of use, particularly in developing countries, in defining national policies on the ethics of biomedical research, applying ethical standards in local circumstances, and establishing or redefining adequate mechanisms for ethical review of research involving human subjects." This document was updated in 1993, 2002, 2009, and 2016 [12]. In 2019 another report on "Clinical Research in Resource-Limited Settings" was published with "the aim to provide balanced arguments to promote scientifically sound good quality clinical research in low-resource settings" [13].

Another International standard includes the guideline of the International Council for Harmonisation of Technical Requirements for Pharmaceuticals for Human Use (ICH) [14]. This council, since 1990, brings "together the regulatory authorities and pharmaceutical industry to discuss scientific and technical aspects of pharmaceuticals and develop ICH guidelines." Throw worldwide harmonization the guidelines intend 'to ensure that safe, effective and high-quality medicines are developed and registered and maintained in the most resource-efficient manner whilst meeting high standards.'

Despite of this ethical recommendation, there are some medical actions that are in the boundary between qualitative improvement practice and the development of

Submitted Date: 12 October 2021, Review Date: 14 November 2021, Accepted Date: 17 November 2021 \& Published: 31 December 2021

(C) 2021 by Journal of Regenerative Science | Available on www.jrsonweb.com | DOI:10.13107/jrs.2021.v01.i01.025

This is an open access journal, and articles are distributed under the terms of the Creative Commons Attribution-NonCommercial-ShareAlike 4.0 License (https://creativecommons.org/licenses/by-nc-sa/4.0/), which allows others to remix, tweak, and build upon the work non-commercially, as long as appropriate credit is given and the new creations are licensed under the identical terms. 
generalizable knowledge, characteristic of research. In these activities, practitioners may introduce innovative diagnostic or therapeutics schemes or methodologies in health care. The question is whether these medical activities are considered research, involve human subjects research and whether they should require independent ethics review or not. To answer these questions some concepts will be specified.

Research is defined as a systematic investigation, including research development, testing and evaluation, designed to develop or contribute to generalizable knowledge. An investigation is systematic when involves a prospective plan that incorporates quantitative or qualitative data collection, and analysis data to answer the research question. Knowledge is generalizable if it may be applied to a broad populations or similar situations, further than that being studied [15]. Knowledge obtained from research is usually shared with colleagues, published, presented to academic meetings to influence clinical practice, research designs, or theories.

The research may involve human subjects, who are defined as a living individual about whom an investigator is conducting research. For example, obtaining, using, studying, or analyzing information or biospecimens through intervention or interaction with the individual; or from identifiable private information or identifiable biospecimens. This means that the data obtain is about any characteristic of that person.

An exception is those publications known as case reports, which do not meet the criteria definition of human subject research, because the aim of the intervention is for the best interest of the patient and not the answer of a research issue. The case report is defined as a report that includes three or less records; the intervention does not have a research intention; does not contain elements of a systematic investigation (statistical data analysis); describes an interesting treatment, presentation, or outcome; and does not contain any identifiable information of the patient [16].

However, some issues as the level of risk, the deviation from common practice, potential benefits, and the possibility of introduction as an ordinary procedure should be addressed, to consider whether the risk the patient will be exposed to requires an objective and independent ethic assessment.

To ensure a rigorous ethical conduct in research studying ethical frameworks and codes based on rules and sets of principles is not enough [17]. It is necessary to develop core competencies in ethics as skills, knowledge, and personal attributes to identify the ethical issues that may raise. These competencies may be acquired by training of researchers and students in responsible conduct, ensuring continuing education in ethics, instituting a clear legal framework, and applying basic principles as the acknowledgment of the own responsibility in the protection of the dignity, welfare, and rights of the patients or research participants. Through understanding the basics of the ethics, the awareness of the medical ethics in the health care can be increased [18].

Practitioners, institutions, academic organizations, or scientific journals should develop transparent internal ethics recommendations, recognizing that ethics awareness should become embedded into practices and researchers' behaviors [19].

Declaration of patient consent: The authors certify that they have obtained all appropriate patient consent forms. In the form, the patient has given his consent for his images and other clinical information to be reported in the Journal. The patient understands that his name and initials will not be published, and due efforts will be made to conceal his identity, but anonymity cannot be guaranteed.

\section{Conflicts of Interest: Nil. Source of Support: None.}

\section{References}

1. Gelijns AC, Rosenberg N, Moskowitz AJ. Capturing the unexpected benefits of medical research. NEngl J Med 1998;339:693-8.

2. McCormick JB, Sharp RR, Ottenberg AL, Reider CR, Taylor HA, Wilfond

$B S$. The establishment of research ethics consultation services (RECS): An emerging research resource. Clin Trans/ Sci 2013;6:40-4.

3. Sharp RR, Taylor HA, Brinich MA, Boyle MM, Cho M, Coors M, et al. Research ethics consultation: Ethical and professional practice challenges and recommendations. Acad Med 2015;90:615-20.

4. Grodin MA, Annas GJ. Legacies of Nuremberg: Medical ethics and human rights. JAMA 1996;276:1682-3.

5. Annas GJ, Grodin MA, editors. The Nazi Doctors and the Nuremberg Code: Human Rights in Human Experimentation. New York: Oxford University Press; 1992.

6. U.N. Universal Declaration of Human Rights. Available from: https://www.un.org/en/about-us/universal-declaration-of-human-rights [Last accessed on 2021 Oct 13].

7. Rice TW. The historical, ethical, and legal background of humansubjects research. Respir Care 2008;53:1325-9.

8. World Medical Association, Declaration of Helsinki, Ethical Principles for Medical Research Involving Human Subjects. Available from: https://www.wma.net/policies-post/wma-declaration-of-helsinki-ethicalprinciples-for-medical-research-involving-human-subjects [Last accessed on 2021 Oct 13].
9. World Health Organization. Research Ethics Committees: Basic Concepts for Capacity-building. Geneva: World Health Organization; 2009 Ava ila ble from: https://www.who.int/ethics/ethics_basic_concepts_eng.pdf [Last accessed on 2021 Oct 13].

10. Council of Europe, Steering Committee on Bioethics. Guide for Research Ethics Committee Members; 2010. Available from: https://www.coe.int/t/dg3/healthbioethic/activities/02_biomedical_researc h_en/Guide/Guide_EN.pdf [Last accessed on 2021 Oct 13].

11. The National Commission for the Protection of Human Subjects of Biomedical and Behavioral Research. Belmont Report, Ethical Principles and Guidelines for the Protection of Human Subjects of Research. Available from: https://www.hhs.gov/ohrp/regulations-and-policy/belmontreport/read-the-belmont-report/index.html [Last accessed on 2021 Oct 13].

12. CIOMS International Ethical Guidelines for Health-related Research Involving Humans. Geneva: CIOMS; 2016. Available from: https://www. cioms. ch/wp-content/uploads/2017/01/WEB-CIOMSEthicalGuidelines.pdf [Last accessed on 2021 Oct 13].

13. CIOMS Clinical Research in Resource-limited Settings. Geneva: CIOMS; $\quad 2021 . \quad$ Ava ilable from: https://wwww.cioms.ch/publications/product/clinical-research-in-lowresource-settings [Last accessed on 2021 Oct 13].

14. International Council for Harmonisation of Technical Requirements for 
Pharmaceuticals for Human Use. Available from: https://www.ich.org [Last accessed on 2021 Oct 13].

15. Emanuel EJ, Wendler D, Grady C. What makes clinical research ethical? JAMA 2000;283:2701-11.

16. Sugarman J. Methods in Medical Ethics. Washington, DC: Georgetown University Press; 2001.
17. Martinson B, Anderson M, de Vries R. Scientists behaving badly. J Nat 2005;435:737-8.

18. Amer A. The health care ethics: Overview of the basics. Open J Nurs 2019;9:183-7.

19. Samuel G, Chubb J, Derrick G. Boundaries between research ethics and ethical research use in artificial intelligence health research. J Empir Res Hum Res Ethics 2021;16:325-37.
Conflict of Interest: NIL

\section{Source of Support: NIL}

\section{How to Cite this Article}

Moya G| Introduction to Bioethics: The Boundary between Research and Clinical Practice | Journal of Regenerative Science | December 2021; 1(1): 48-50. 